\title{
LA BRUJA COMO ENTE FICCIONAL EN LA TRADICIÓN HISPÁNICA ÁUREA: UNA NUEVA APROXIMACIÓN AL CONTROVERTIDO FENÓMENO DE LA BRUJERÍA A LA LUZ DE LA LITERATURA ${ }^{1}$
}

EVA LARA ALBEROLA ${ }^{2}$

Universidad Católica de Valencia

\begin{abstract}
Resumen
El presente trabajo profundiza en la bruja como personaje literario en las letras áureas. Partiendo de un análisis de todos los textos de los siglos XVI y XVII existentes en los que la bruja participa de algún modo, llegaremos a la conclusión de que este actante no abunda en las obras del periodo abarcado en la medida esperable, pues la eclosión de la caza de brujas tuvo lugar durante las mencionadas centurias. Por ello, nos hemos centrado posteriormente en otros materiales que pueden desvelar cómo el arquetipo de la bruja se ha difundido, a pesar de su pobre recreación en la literatura de ficción de estos siglos: los tratados y relaciones de procesos inquisitoriales. Estos géneros son los que realmente proporcionan la clave para comprender dónde y cómo nace y se desarrolla la figura que nos interesa; y conducen al investigador a plantearse nuevas tesis para abordar el fenómeno de la brujería.
\end{abstract}

Palabras clave: brujería - literatura - tratadística - tradición oral.

\begin{abstract}
This in-depth research deals with the witch as a literary character in the Golden Age. From the analysis of all the existing $16^{\text {th }}$ and $17^{\text {th }}$ century texts where the witch appears in some way, it will finally prove that this character is not abundant as it should be expected in the works of the period, since the emergence of witch-hunting took place during the aforementioned centuries. Therefore, we have subsequently focused on other texts that may reveal how the archetype of the witch has been spread out, despite its poor presence in the fictional literature of these centuries: the treaties and documents of the inquisitorial processes. These genres are the ones that actually provide the key to understand where and how the figure that interests us was born and developed, and they lead the researcher to look for new thesis to approach the phenomenon of witchcraft.
\end{abstract}

Key words: witchcraft - literature - treatises - oral tradition.

1 Universidad Católica de Valencia. Correo: Recibido: 19-12-2011; Aceptado: 31-01-2012.

2 El presente trabajo se ha realizado en el marco del Proyecto del Plan Nacional I+D+I con referencia FFI2011-25429, "Parnaseo (Servidor Web de Literatura Española)", dirigido por la dra. Marta Haro Cortés y financiado por el Ministerio de Ciencia e Innovación. 


\section{Introducción.}

La brujería es y sigue siendo uno de los fenómenos históricos, antropológicos, teológicos, psicológicos y literarios más complejos y controvertidos de cuantos existen, puesto que no han podido desentrañarse con seguridad ni su origen exacto, ni su significación, ni su auténtica naturaleza.

Para profundizar en este espinoso asunto es necesario auxiliarse de distintas disciplinas, como las arriba enumeradas, pero, sin lugar a dudas, uno de los puntos de apoyo más importantes a la hora de interpretar la brujería es, a la luz de nuestras últimas indagaciones, la literatura. Por ello, sirviéndonos de esta herramienta ahondaremos profundamente en este movimiento dura $\mathrm{y}$ cruelmente perseguido por la justicia, sobre todo en los siglos XVI y XVII, y adscrito, básicamente, a la feminidad.

La brujería, que parte de la hechicería y que la trasciende, es decir, deja de ser simple hechicería para convertirse en mucho más que eso; debe tomarse como una secta organizada de adoradoras de Satán, que acuden regularmente a los aquelarres, vuelan montadas en escobas $\mathrm{u}$ otros artilugios variados (tras untarse con un preparado diseñado para tal efecto con numerosas sustancias sobre la naturaleza de las cuales se ha discutido ampliamente) y no dudan en arrancar a tiernos infantes de sus cunas, ofrecerlos al diablo e incluso asesinarlos o chuparles la sangre; practican todo el mal que está en su mano para fortalecer a su señor. Este cúmulo de creencias sobre las que apenas hemos ofrecido una aproximación, en referencia a en qué consiste tal fenómeno, ha resultado, como decíamos, francamente llamativo; no solo por su complejidad, pues no se ha logrado, todavía, desentrañar con seguridad el origen de la brujería ni comprender todos sus recovecos; sino también por las consecuencias 
tangibles que la creencia en este grupo y sus andanzas ocasionó, y que se conoce como caza de brujas ${ }^{3}$.

La representante encarnada de este fenómeno fue la bruja (más que el brujo), de la que se espera una gran presencia en las letras áureas ${ }^{4}$, pues la eclosión de la persecución brujeril se da en los Siglos de Oro.

La bruja, a caballo entre el mito y la realidad, poblaba ya el folclore, habitaba en la mente y en la palabra de las gentes, en las historias que circulaban en los pueblos, en las aldeas, o que se emitían desde el púlpito, e innegablemente se había instalado en la mente de los hombres y las mujeres de los siglos XVI y XVII. Por ello, resulta sorprendente que hallemos una cantidad tan pobre de brujas en la literatura de dichas centurias.

Veamos las muestras más representativas, tomando como base, casi única y exclusivamente, las letras de ficción.

\section{1.- La bruja en la literatura española de los Siglos de Oro.}

La primera mención brujeril digna de consideración, realizada ya en el marco de la literatura renacentista, tiene lugar en La Celestina (1499), de Fernando de Rojas. Resulta indispensable, antes de pasar adelante, aclarar que no nos referimos a las ocupaciones hechiceriles de la criatura rojana, sino a los aspectos puramente brujeriles. De ahí que solo nos interese, en el caso de La Celestina, el

\footnotetext{
3 Julio Caro Baroja relaciona la hechicería con la práctica solitaria y urbana y la brujería con la práctica comunitaria y rural (aquelarres) (1995, pp. 33-35). Es cierto que la bruja forma parte de una Tolivar Alas, A. C., sociedad secreta a la cabeza de la cual se encuentra el diablo y que la hechicera no cierra, por regla general, ningún pacto explícito que la adscriba a un grupo organizado. Se podría ampliar esta diferenciación argumentando que la bruja posee unos poderes y capacidades de carácter mágico en tanto ha establecido un trato con el demonio; la hechicera puede poseer unos conocimientos mágicos en virtud de un aprendizaje o una herencia, que, eso sí, pueden colindar con lo diabólico, dependiendo de qué tipo de prácticas ejecute.

${ }^{4}$ De hecho, Yolanda Beteta afirma que "el estereotipo de monstruo femenino que más ha trascendido en la cultura popular es el de la bruja" (2011, p. 101).
} 
momento exacto en el que leemos, cuando la alcahueta habla sobre su maestra, Claudina:

[...] Hijo, digo que sin aquélla prendieron quatro vezes a tu madre, que Dios haya, sola. Y aun la una le levantaron que era bruxa, porque la hallaron de noche con unas candelillas cojendo tierra de una encruçijada, y la tovieron medio día en una escalera en la plaça puesta, uno como rocadero pintado en la cabeza (La Celestina: 197-198).

No queda demostrada esa acusación de brujería que cae sobre Claudina, pues se usa la expresión "le levantaron", que se refiere al falso testimonio. Interesa esta cita solo en la medida en que la idea de la brujería se halla presente en uno de los textos más importantes de la tradición hispánica.

La Farsa del Nascimiento (h. 1500), de Lucas Fernández, también presenta una mención de la brujería, muy tangencial, mas significativa por dos razones: en primer lugar, al igual que sucede en La Celestina, se acusa a la mujer en cuestión de bruja porque frecuenta las encrucijadas; en segundo lugar y en conexión con la primera observación, se vincula esta práctica con las zonas rurales, pues el cruce de caminos siempre se da en lugares apartados.

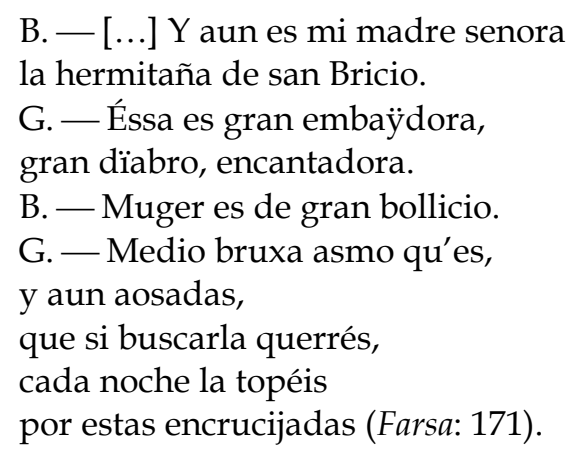

El Auto das fadas (1511-1527), de Gil Vicente, aporta más información acerca de este actante, tan escurridizo. Genebra Pereira, la protagonista de este auto, desglosa su variopinto oficio mágico. Se trata de una hechicera de tomo y lomo, pero aderezada también por algunos toques brujeriles, que se evidencian en sus alusiones, nuevamente, a las encrucijadas, y añade otros elementos que son los 
que realmente definen a la brujería: cabalga sobre un cabrón hasta el Val de Cavalinhos.

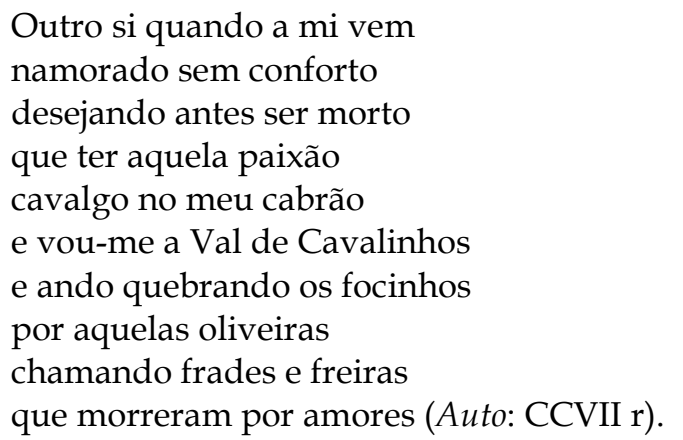

Se refiere al vuelo típico de las brujas sobre diversas clases de bestias, rumbo al aquelarre. Vemos como se va completando un retrato que en ningún caso, hasta el momento, aparece aisladamente, es decir, por ahora las brujas son sobre todo hechiceras, que completan sus andanzas sobrenaturales con una adscripción, real o supuesta, a una sociedad secreta capitaneada por el diablo.

Antonio de Torquemada, en su miscelánea Jardin de flores curiosas (1570), ofrece una definición de bruja (brujo en este caso) y aporta ejemplos, casos, que proceden bien de fuentes librescas, bien de la tradición oral ${ }^{5}$, e ilustran literariamente aquello que primero se ha ofrecido de modo teórico. Se pasa de las piezas de ficción a un género que pretende divulgar unos contenidos destinados, hasta ese momento, a eruditos e intelectuales. No estamos ante una trama ficcional, sino ante una obra dialogada en la que se conversa acerca de diferentes temas raros y curiosos, entre ellos no podía faltar la brujería:

Los brujos se conciertan expresamente con el demonio y lo toman y obedecen por señor, y se dejan señalar de él por esclavos suyos, les ponen una señal. Hacen hermandad y cofradía y se juntan cada cierto tiempo para sus maldades y deleites infernales; y cuando así hacen estos ayuntamientos, siempre hacen su acatamiento y reverencia al demonio, el cual, por la mayor parte, se les muestra y aparece en figura de cabrón, y son tantas y tan abominables las que de ellos se cuentan que nunca acabarían de decirse (Jardin: 180-181).

\footnotetext{
5 También Rallo (en prensa) considera que en este texto se da "la combinación de los
} conocimientos eruditos con los casos de tradición oral". 
La bruja se caracteriza por el pacto expreso que cierra con el diablo, el cual la convierte en su sierva y la compromete a personarse en las periódicas reuniones en las que todos los brujos se congregan. No se aportan más detalles, pero con estas palabras de don Antonio se puede comprender bien la naturaleza de la brujería.

Más adelante, uno de los dialogantes, Luis, alude a Fray Alonso de Castro como autoridad y, basándose en este teólogo, profundiza un poco más en las malsanas costumbres de los brujos y brujas:

[...] Este linaje de hombres y mujeres solamente se conciertan con el demonio para gozar en esta vida de todos los deleites y placeres que pueden; y que cuando la primera vez que van a hallarse delante del demonio y hacerle reverencia, que no le hallan en figura de cabrón, sino de un rey de mucha autoridad; y que todos los brujos y las brujas son llevados por demonios en figura de cabrones, a los cuales llaman martinetes, y que en la reverencia y acatamiento que le hacen no es como nosotros lo hacemos, sino volviéndole las espaldas y bajando la cabeza para atrás todo lo que pueden; [...] y hecho esto, se juntan todos, y muchos demonios con ellos en figura de gentiles hombres y hermosas mujeres, y se mezclan a rienda suelta, cumpliendo sus desordenados apetitos; y de esta compañía las más, o casi todas dicen que son mujeres, como más aparejadas, así para ser engañadas del diablo, como para caer en el pecado de la lujuria (Jardín: 182-183).

Para conocer mejor a estas mujeres sobrenaturales los cuentos que salpican la obra son una referencia obligada y poseen el mérito de convertir a la figura que nos interesa en un ente ficcional, que protagoniza textos literarios, aunque muy breves, frente a la mera mención que se hace en otras piezas.

Seis son los relatos que aderezan el segmento del tratado que se dedica a la temática brujeril. En el primero, extraído del Malleus Maleficarum, se muestra cómo una supuesta bruja provoca una tormenta, usando su orina como materia prima para el hechizo:

[...] haciendo un hoyo en la tierra con las manos, orinó dentro de él, y metiendo un dedo comenzó a revolver la orina, de la cual, poco a poco, con ciertos caracteres y palabras que la hechicera dijo e hizo, salía un vapor que, a manera de humo, subía para arriba, y comenzándose a espesar en medio de la región del aire, vino a hacer una nube tan negra y temerosa, y comenzó a echar de sí tantos truenos y relámpagos, que parecía cosa infernal (Jardín: 136-137). 
El siguiente ejemplo se expone como real, de observación directa, y narra la historia de amor entre una bruja y el diablo, que la engaña vilmente, haciéndose pasar por gentilhombre, el cual, finalmente, la abandona a su suerte:

[...] siendo la doncella presa por ello, jamás se pudo acabar con ella que se reconciliase, antes muy obstinada en pensar que el demonio la había de valer como le había prometido, y también en la afición y amor que con él había tomado, sobre lo cual decía muchas cosas que espantaban a los que la oían, con su pertinacia y engaño dejó meterse viva en el fuego, llamando siempre por él, a donde recibió el pago que merecía de su locura (Jardín: 159-160).

A continuación, se facilita una anécdota, que al interlocutor le contaron, sobre un brujo que lleva consigo a un letrado a uno de los aquelarres, y los avatares que allí le sucedieron al segundo, en el que no nos detendremos (Jardin: 181-182).

Las dos narraciones siguientes sirven para ilustrar primero el caso de vuelo real (el ejemplo proviene de Pablo Grillando) y después el ilusorio (extraído del Malleus). En el primer relato la bruja, que viaja corporalmente al aquelarre recibe una valiosa lección:

[...] Una mujer en Italia, que había probado esta arte diabólica, vino a ser llevada por el demonio a hallarse en uno de sus ayuntamientos, y como ya volviese para su casa, habiendo gozado de aquellos sucios y abominables deleites, siendo cerca de la mañana, sonó la campana que en Italia se acostumbra a tañer a aquella hora, para amonestar al pueblo que hagan oración, y en oyendo el sonido, el demonio que le traía la soltó y se fue, y ella quedó en un campo muy lleno de espinas (Jardín: 185-186).

Finalmente, pide ayuda a un mancebo que pasaba por allí, que resulta ser un vecino suyo y que, aunque la asiste en ese momento, finalmente la delata. La segunda anécdota trata de unos inquisidores que someten a una bruja presa a un experimento, para comprobar si el viaje al aquelarre se da o si todo es un sueño:

Y como se quedase sola y encerrada, prometiendo que haría verdad lo que decía, los Inquisidores, esperando un rato, mandaron abrir por fuerza la puerta, y entrando en la cámara, la hallaron en medio de ella tendida y tan sin sentido, que verdaderamente parecía que estuviese muerta (Jardín: 186). 
Uno de ellos la quema con una vela en la pierna, para mostrarle después que no se ha movido de la estancia, y así queda muy escarmentada de la falacia de la brujería.

El último de los fragmentos que Torquemada trae a colación la historia de una bruja que es descubierta por su marido en sus aventuras nocturnas:

[...] estando ella una noche en una cámara cerrada, él la miraba por un pequeño agujero que había hecho, y vio que se estaba untando con cierta unción que allí tenía; y en acabando de hacerlo, le pareció que en figura de ave se había puesto encima del tejado de la casa; y siguiéndola, por ver lo que hacía, no la pudo ver más, y descendiendo a la puerta de su casa, hallola cerrada, y así, quedó muy maravillado (Jardin: 187-188).

La mujer se ve obligada a confesar a su marido su auténtica identidad, y se encuentra con que lo que él realmente desea es acompañarla a las reuniones. Y así sucede, aunque la diversión no termina bien para el esposo curioso, pues menciona el nombre de Dios y todo se desvanece a su alrededor; queda solo y lejos de su hogar, aunque logra regresar a su pueblo y dar parte a la justicia.

Esta sucesión de episodios ficcionales, cuyo objeto central es la bruja, a modo de recopilación de cuentos populares, no se va a repetir en demasiadas ocasiones. Hallamos, eso sí, en la Silva curiosa (1583), de Julián Medrano, una historia protagonizada por Orcavella, aunque, en ningún caso, se le da la palabra a la bruja, es el narrador en tercera persona quien filtra los hechos. Orcavella, una vieja hechicera descendiente directa de féminas semimonstruosas como la Canidia horaciana y la Ericto lucaniana, representa el estado intermedio entre la simple hechicera y la terrible bruja, mas no puede catalogarse como una bruja por la ausencia de referencias directas a hechos consustanciales a la brujería. No obstante, las alusiones al infanticidio y el vampirismo ("Ella se hazía invisible quando quería, y se transformava en diversas formas. Ella robava de noche y de día quantos niños podía, y con la carne y sangre de aquellas pobres criaturas innocentes mantenía su vida" [Silva: 288]) nos dejan la sensación de estar siempre a punto de sorprender a esta anciana bárbara y cruel volando en escoba para acudir a un conventículo diabólico, pero esto nunca sucede (Silva: 288-290). 
Fray Prudencio de Sandoval, en su Historia de los hechos del Emperador Carlos $V$ (1604), sitúa al lector frente a auténticas brujas, en el marco de una investigación y un proceso por brujería, en 1527, en Navarra. Dos niñas son quienes prenden la llama de la sospecha y las acusaciones. Fray Prudencio intriga al receptor con un increíble relato acerca de cómo las dos pequeñas, por separado y atendiendo únicamente al ojo izquierdo de los vecinos, señalan exactamente a las mismas personas. Pero lo realmente aterrador es el experimento que realizan los inquisidores con una de las viejas brujas presas, ya que le piden que les muestre de qué manera va a hacer sus obras:

Ella [...] pidió un bote de ungüento que le habían tomado, con el cual se puso en la ventana de una torre muy alta, y en presencia de mucha gente se untó con aquel unto [...]. Y esto hecho, dijo en voz alta: «¡Ay!» A la cual voz respondió otra, dijo: «Sí, aquí estoy.». Y luego [...] se bajó por la pared abajo, la cabeza abajo, [...] como una lagartija; [...] levantóse en el aire a vista de todos y se fué volando por él (Historia de los hechos: 251).

Estos intentos, siempre presentes en géneros como la miscelánea, el tratado teórico o las relaciones de hechos, con una importante raigambre real o pretendidamente real, encuentran un pobre reflejo en otros géneros, lo cual impide el desarrollo y la consolidación de la bruja como personaje de ficción. Cuando se trata de componer, inventar un argumento aderezado por una bruja, que represente todo lo que la brujería de la época simboliza, contamos con escasa materia prima.

Quevedo, en El Buscón, no renuncia a hacer de la madre de Pablos, Aldonza de San Pedro, una bruja. Ella misma reconoce sus ocupaciones cuando le refiere a su marido: "Y si no temiera que me habían de oír en la calle, yo dijera lo de cuando entré por la chimenea y os saqué por el tejado" (Buscón: 836). Se trata de apenas una mención, pero que agrava la condición de la progenitora de Pablos. La brujería se extiende desde las zonas rurales hasta las urbanas, y abunda en la picaresca, pero como un detalle más que define de modo harto negativo a aquellas que han dado la vida al pícaro/a o que lo rodean y acompañan (Lara Alberola: 2008), pues sucede algo muy similar con doña Lucía, la vieja morisca 
con la que Justina, de La pícara Justina, de Baltasar de Navarrete, comparte vivienda y experiencias durante algún tiempo. Afirma la pícara: “Siempre yo entendí della que era bruja, y no me engañaba, porque ella hacía unos ungüentos y unos ensalmos que no era posible ser otra cosa" (Pícara: 1410).

De ahí que en las letras de ficción solo acudamos a un tipo de brujería narrativa, es decir, contada y cantada, nunca vivida, jamás materializada. $\mathrm{Ni}$ siquiera se da la posibilidad de expresión a la propia interesada de carácter mágico. Se escribe desde la observación, desde la distancia. Justina, por ejemplo, no se involucra, no nos desvela los entresijos más allá de posicionamiento con respecto al vuelo fingido de Lucía, a la que, paradójicamente, hereda:

Ella bien me quisiera enseñar el oficio por pegarme la sarna. [...] Pero no quise, lo principal, por temor de Dios, y lo segundo, porque siempre fui enemiga de oficios que se hacen medio durmiendo como este de la brujería, en el cual por la mayor parte -como yo vía- las brujas se quedan amodorridas de sueño, y lo que en sueños hacen les persuade el diablo que es de veras, con unos enredos que, si los hubiera de contar como ella me los refirió, nunca acabara (Pícara: 1410-1411).

La Cañizares de El Coloquio de los perros (1613), de Cervantes, se reconoce bruja: "Bruja soy, no te lo niego; bruja y hechicera fue tu madre, que tampoco te lo puedo negar" (Coloquio: 340). Ahora sí estamos ante una mujer con voz, también la tenían Aldonza y doña Lucía, mas en menor medida, y nunca para realizar consideraciones analíticas tan profundas con respecto a la brujería. La Cañizares es como un teólogo con disfraz de anciana dedicada a menesteres heterodoxos:

Este ungüento con que las brujas nos untamos es compuesto de jugos de hierbas en todo extremo fríos, y no es, como dice el vulgo, hecho con la sangre de los niños que ahogamos. [...] Las unturas son tan frías que nos privan de todos los sentidos en untándonos con ellas, y quedamos tendidas y desnudas en el suelo, y entonces dicen que en la fantasía pasamos todo aquello que nos parece pasar verdaderamente. Otras veces, acabadas de untar, a nuestro parecer mudamos de forma, y convertidas en gallos, lechuzas o cuervos, vamos al lugar donde nuestro dueño nos espera, y allí cobramos nuestra primera forma, y gozamos de los deleites que te dejo de decir [...] (Coloquio: 341). 
Y Berganza va a tener ocasión de presenciar el supuesto viaje de la bruja al aquelarre. Esa experiencia lo sitúa en la tesitura de poder describir físicamente a la Cañizares:

Ella era de larga de más de siete pies; toda era notomía de huesos, cubiertos con una piel negra, vellosa y curtida; con la barriga, que era de badana, se cubría las partes deshonestas, y aun le colgaba hasta la mitad de los muslos; las tetas semejaban dos vejigas de vaca secas y arrugadas; denegridos los labios, traspillados los dientes, la nariz corva y entablada, desencaxados los ojos, la cabeza desgreñada, las mejillas chupadas, angosta la garganta y los pechos sumidos; finalmente, toda era flaca y endemoniada (Coloquio: 344 ).

Estamos viendo a una de las brujas goyescas, monstruosa y a la vez risible.

Esta bruja, que posee el mérito de ser un ente ficcional con posibilidad de expresión, no se sitúa lejos de la tratadística, de la cual hace uso Cervantes para construir a su personaje y su trama brujeril. Este autor no corre el riesgo que supondría dar a la Cañizares su propia voz, ya que intuimos, tras sus palabras, el susurro de los teólogos e inquisidores ${ }^{6}$. Falta todavía el salto que operará aquel que se atreva a conducirnos, materialmente, al aquelarre.

El Entremés famoso de las brujas (1654), de Agustín Moreto, alude a la brujería, pero, en realidad, solo hallamos a brujas fingidas, ladrones disfrazados que, bajo dicha máscara mágica, llevan a cabo sus delitos impunemente. Todo el enredo gira en torno a esa identidad fingida y la credulidad de algunos personajes, como el alcalde de la aldea que está siendo asolada:

\footnotetext{
Alc.- He querido juntaros a Concejo, para poner remedio, como viejo, en esto de las brujas, que han venido diez noches, y la gente no ha dormido, de la sangre de niños tan sedientas, para hacer sus hechizos avarientas.

Reg. $1^{\circ}$. Es gente que en una hora se ponen desde Flandes a Zamora

Alc.- Tú mucho dellas sabes, pues nos cuentas que andan como aves. De una pierna una noche me cogieron,
}

\footnotetext{
6 Para García Soormally, 2011, p. 522, la Cañizares adopta el lenguaje característico de los tratados y procesos para "justificar su abandono de una sociedad mayoritaria y para evidenciar que, ante la decadencia del centro, los márgenes se mantienen apartados por una razón: son consecuentes".
} 
Aunque las brujas que aquí se mencionan no sean reales, sí resulta relevante que se relacionen ciertas características que ya les son inherentes, como su vampirismo, la posibilidad del vuelo...

Un hecho muy similar topamos en Entremés de las brujas fingidas y berza en boca (1712, posiblemente de la primera mitad del XVII), que puede que sea de Quiñones de Benavente, según Abraham Madroñal7.

En esta pieza se perpetúan elementos que ya hemos visto con anterioridad, y se resaltan otros que convierten la vida brujeril en toda una fiesta, pues se hace hincapié en el aspecto alimenticio de la secta, pues el aquelarre se caracteriza por el banquete. No falta la reiteración del vampirismo de las brujas, que aquí también son fingidas; nos hallamos ante unos pillos que no desean más que arrebatar la bolsa al gracioso.

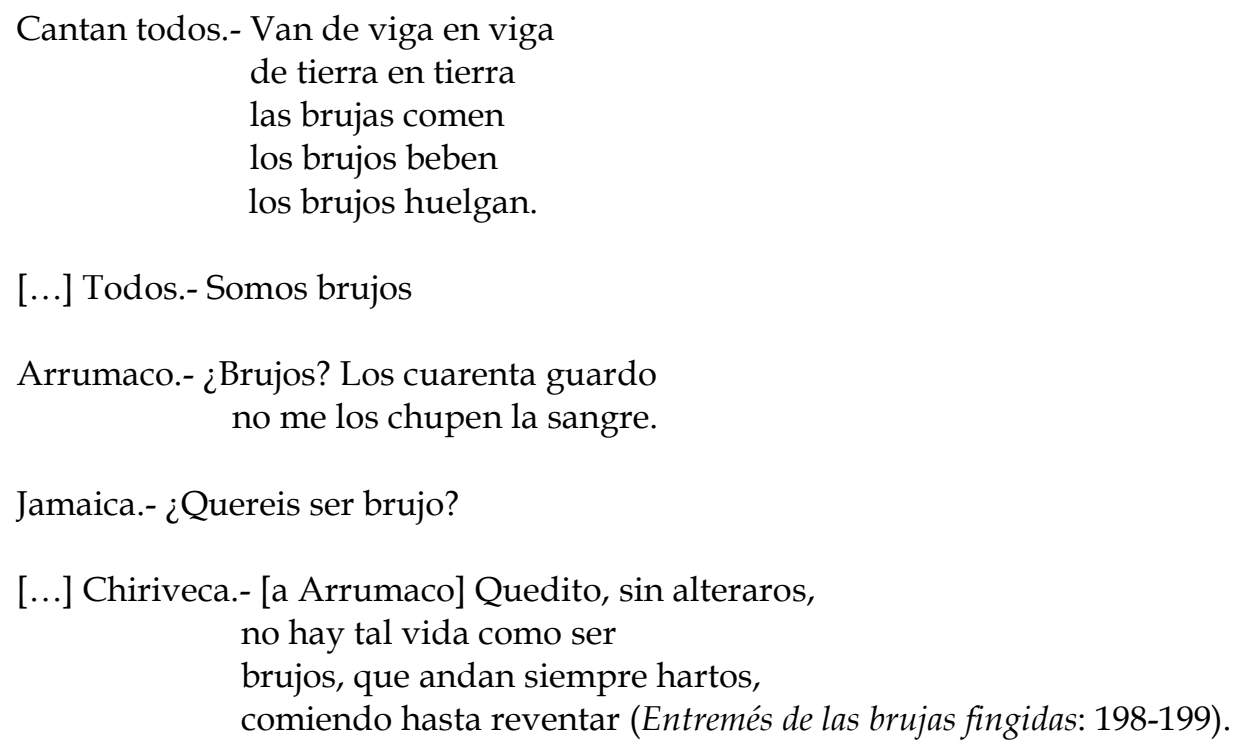

El Entremés de las brujas (principios del siglo XVIII, editado en 1742), de Francisco de Castro, cambia ya esta perspectiva, aunque es, también, más tardío que los textos anteriores. En esta ocasión, el autor aprovecha una historia

\footnotetext{
${ }^{7}$ Cotarelo afirma que pudo ser compuesto en la primera mitad del siglo XVII y Abraham Madroñal ha argumentado que su autor podría ser Quiñones de Benavente (Lobato (ed.), 2003: 78).
} 
conocida, reseñada por Antonio de Torquemada en su Jardín de flores curiosas, tomada, a su vez, de Pablo Grillando, y la transforma en un entremés.

Por fin, vamos a ver a una auténtica bruja en acción. Zeledonio, su marido, ha descubierto sus actividades: entre las que se encuentra el unto, precedente al vuelo. Este buen hombre envidia la existencia que lleva su mujer y la obliga a transportarlo con él al conventículo, que se presenta como una celebración de carácter popular (Entremés de las brujas: 66).

Se asiste de primera mano al banquete, mas poco dura tal gozosa situación, pues este intruso a la secta pronuncia el nombre de Dios y todo se desvanece, y él queda perdido en lejanas tierras.

Pasamos, por tanto, de la simple mención que se opera en los primeros textos mencionados, tales como La Celestina, la Farsa del Nacimiento o el Auto das fadas, en los que a la hechicería se unen tintes brujeriles que están por comprobar, a una profundización mayor en los entresijos de esta sociedad secreta en la miscelánea y la relación de hechos históricos, que beben tanto de la supuesta realidad como de toda la tradición libresca y popular generada en torno a este fenómeno; y cuando parece que hemos llegado a buen puerto, solo topamos de nuevo con brujas en las que sigue primando su condición hechiceril y de las que solo tenemos palabras, nunca hechos, como sucede con Aldonza y doña Lucía. El gran hito parece ser la Cañizares cervantina, pues es una bruja con voz y casi con voto, aunque pronto descubrimos que, en realidad, es más un teólogo o inquisidor enmascarado, por lo que Cervantes permanece dentro de la ortodoxia religiosa en todo momento. Y, finalmente, llegamos a la bruja entremesil, en muchas ocasiones fingida (en esas ocasiones se usa como una máscara y, como tal, vacía de contenido pero plena de significado) y, en todo caso, siempre se resaltan los aspectos más atractivos de la secta, aquellos que más atraen a un público popular, con lo que se contrarresta cualquier posibilidad terrorífica.

En esta larga pero escasa cadena de transmisión faltan eslabones que nos permitan explicar la consolidación de la bruja como ente ficcional. Por una 
parte, podríamos interrogarnos sobre la razón por la cual este arquetipo no despunta en relatos de terror, por ejemplo (pensemos en las novelas cortas de María de Zayas, en las que sí se vincula a la hechicera con hechos siniestros), pero el género de terror apenas está comenzando a germinar. Tendremos que aguardar hasta el siglo XIX, en el que por fin nacerá la novela gótica y el Romanticismo permitirá a escritores como Bécquer transformar a la bruja en un ser que causa pavor ${ }^{8}$.

De otro lado, no podemos dejar de reflexionar acerca de si, en efecto, la brujería en España tuvo el calibre suficiente como para poblar los libros en la medida en que lo había hecho la hechicera. En primer lugar, no sería nada fácil jugar con un actante heterodoxo de tan rabiosa actualidad que podía ocasionar problemas al autor que se atreviera a traspasar la fina línea que separa lo permitido de lo prohibido. En segundo lugar, en nuestra país no arraigó la brujería tanto como en otros países europeos; sí lo hizo, hasta límites insospechados, la hechicería; de ahí que la literatura se incline más por un personaje que, por una parte, poseía una firme tradición literaria como base, y que, por otra, era muy cercano para el lector. Quizás la bruja fuera más ajena a la sociedad española del momento y también, dicho sea de paso, a la inquisición peninsular 9 .

De todos modos, a pesar de estas posibles razones aducidas, siguen faltando varios eslabones en la cadena de transmisión brujeril, y parte de ellos podrían completarse con un estudio de la tradición oral-popular que existió en torno a la bruja, mas no se trata de un terreno fácil, ya que este personaje no aparece en

\footnotetext{
8 Pensemos también en Valle-Inclán, que en gran parte de su producción, al reflejar en sus piezas la superstición popular gallega, da cabida a brujas de distinta raigambre, ya como personajes de ficción, aunque intentan ser un espejo de esa realidad mágica propia de las tierras de Galicia.

9 Joseph Pérez, en su reciente estudio, Historia de la brujería en España, afirma: "En España, la brujería moderna [...] es un fenómeno que solo está documentado en los montes del norte de la Península: en las provincias vascas, en Navarra, en el Pirineo aragonés y catalán; en el resto de España, lo que se encuentra es más bien la hechicería tradicional" $(2010,172)$.
} 
las recopilaciones de cuentos áureos ${ }^{10}$. Solo podremos avanzar en nuestras indagaciones si acudimos a la tratadística hispánica áurea.

\title{
2.- La bruja en los tratados españoles de los Siglos de Oro.
}

Fray Martín de Castañega, en su Tratado de las supersticiones y hechicerías, distingue dos iglesias, una católica y otra diabólica. A esa iglesia diabólica pertenece, según él, la bruja:

Los unos y los otros que por pacto expreso están al demonio consagrados, se llaman por vocablo familiar brujos o xorguinos. [...] Y este nombre bruja es vocablo italiano que quiere decir quemado o quemada, porque la pena de los semejantes sortílegos y magos era que los quemaban y así les quedó tal nombre (Tratado de las supersticiones: 33 ).

De la misma manera, Castañega afirma: "De estos ministros al demonio consagrados y dedicados, más hay mujeres que hombres" (Tratado de las supersticiones: 35) (lo cual él justifica con diferentes argumentos). Y añade:

\begin{abstract}
Y más son de las mujeres viejas y pobres que de las mozas y ricas porque, como después de viejas, los hombres no hacen cado de ellas, tienen recurso al demonio, que cumple sus apetitos, en especial si cuando mozas fueron inclinadas y dadas al vicio de la carne; a estas semejantes engaña el demonio cuando viejas, prometiéndoles de cumplir sus apetitos y cumpliéndolos por obra. [...] Y más hay de las pobres y necesitadas porque, como en los otros vicios, la pobreza es muchas veces ocasión de muchos males en las personas que no la toman de voluntad o paciencia; por esto, pensando que el demonio suplirá sus necesidades o responderá a sus deseos o apetitos, más son engañadas las viejas y pobres que no las mozas y las que tienen bien lo que han menester (Tratado de las supersticiones: $36-37)$.
\end{abstract}

${ }^{10}$ Existe una tesis doctoral, inédita, de Donna Fields, centrada en El protagonismo de la bruja tutelar en el cuento folklórico maravilloso: análisis de personajes, argumentos y motivos en un corpus hispánico y universal, que profundiza en el personaje que nos interesa desde una perspectiva diferente a todas desde las cuales se ha abordado esta temática hasta hoy. Los relatos analizados en dicho trabajo demuestran que la bruja del folklore es, en la mayoría de ocasiones, difícilmente diferenciable de la hechicera, por lo que no resulta fácil catalogarla efectivamente como bruja y, por tanto, nos hallamos frecuentemente ante una versión desnatada de la mujer amante del diablo que nos interesa. La cualidad que usan los indagadores del folclore para clasificar a estas féminas como brujas es su maldad, aunque solamente tal rasgo no resulta determinante. De ahí que la pactante, que acude al aquelarre y copula con el demonio no se halle presente más allá de ciertas pinceladas que tienen que ver, sobre todo, con el infanticidio y la antropofagia (pensemos en Hansel Y Gretel). 
Castañega se refiere a todas las integrantes de la que él denomina iglesia diabólica, pero su descripción cuadra a la perfección con la figura que nosotros conocemos como bruja. Posteriormente, este teólogo no incide de manera exclusiva y profunda en estas féminas, pero sí va diseminando información de interés al respecto, pues menciona el vuelo y considera que en algunas ocasiones el demonio lleva a sus súbditos en volandas. En cambio, las metamorfosis son una ilusión demoníaca, nunca son reales. Este debate en torno a las cuestiones planteadas nos presenta a la bruja como una mujer que vuela y que, supuestamente, se transforma en diversos géneros de animales. Y no olvida este autor mencionar el vampirismo y el infanticidio, aludiendo, a las parteras brujas. Por último, termina el retrato de la fémina que nos interesa hablando de la herencia matrilineal de la hechicería y la brujería (Tratado de las supersticiones: $39-49)$.

Pedro Ciruelo, en su Reprobación de las supersticiones y hechicerías, proporciona información más precisa acerca ya, concretamente, de la bruja, como un actante mágico diferenciado y único:

También las cosas que hazen las bruxas y xorguinas son tan maravillosas que no se puede dar razón dellas por causas naturales: que algunas de ellas se untan con unos ungüentos y dicen ciertas palabras y saltan por la chimenea del hogar, o por una ventana y van por el aire y en breve tiempo van a tierras muy lejos y tornan presto diciendo las cosas que allá pasan. Otras de estas en acabándose de untar y decir aquellas palabras: se caen en tierra como muertas, frías, y sin sentido alguno: aunque las quemen, o sierren no lo sienten: y de allí a dos o tres horas se levantan muy ligeramente y dicen muchas cosas de otras tierras y lugares a donde dicen que han ido. Otras de estas que caen aunque pierdan todos los otros sentidos les queda la lengua suelta y hablan maravillosos secretos de las ciencias que aprendieron: y de las santas escrituras dan declaraciones maravillosas de que se espantan los muy grandes sabios filósofos y teólogos (Reprobación: 1978).

Este pensador incide sobre todo en el vuelo, como el aspecto no solo más característico, sino también más controvertido y susceptible de análisis:

Vntándose con ciertos vngüentos y diziendo ciertas palabras: van de noche por los ayres y caminan a lexos tierras a hazer ciertos maleficios. Mas esta illusión acontesce en dos maneras principales: que horas ay que ellas realmente salen de sus casas, y el diablo las lleua por los ayres a otras casas y lugares: y lo que allá 
veen, hazen, y dizen passa realmente ansí como ellas lo dizen y cuentan. Otras vezes ellas: no salen de sus casas: y el diablo se reuiste en ellas de tal manera: que las priua de todos sus sentidos, y caen en tierra como muertas y frías. Y les representa en sus phantasías que van a las otras casas y lugares. [...] Y nada de aquello es verdad. [...] Y mientras que ellas están ansí caydas y frías: no sienten más que muertas: avnque las açoten, y hieran y quemen, y les hagan quantos males puedan por acá de fuera en el cuerpo: mas passadas las horas de su conciertos con el diablo: él las dexa y les suelta sus sentidos y se levantan alegres y sanas y dizen que han ydo acá y acullá y cuentan nueuas de otras tierras (Reprobación: 49).

Tampoco Ciruelo aporta una definición de bruja, ni una descripción exhaustiva, pero gracias a los comentarios y disecciones que ejecutan los intelectuales podemos ir construyendo, como si de un rompecabezas se tratara, a esa etérea mujer que, según este teólogo surca los aires, pero que también parece estar fabricada de aire, en tanto inasible e inaprensible. Ni siquiera Ciruelo puede concluir si estas féminas acuden corporalmente al aquelarre; si, en efecto, rasgan sobre su escoba el manto de la noche negra, pues en el terreno diabólico todo es posible, en este caso tanto la realidad como el truco son viables, de modo que ambas vías permanecen igualmente abiertas.

Vayamos un poco más allá y detengámonos brevísimamente en las Disquisiciones mágicas, de Martín del Río.

Una de las primeras referencias que hallamos en torno a la brujería se da en el capítulo 4, cuando este teólogo analiza pormenorizadamente todas las variantes del pacto diabólico. Es entonces cuando menciona la exigencia, por parte del demonio a los que van a ser sus acólitos, de renegar de Dios y la Virgen María, hecho que se imputaba a las brujas; y al hacer alusión a los sacrificios que prometen los seguidores de Satán a su señor, no puede menos que aludir a las estriges, que pretenden asesinar a las tiernas criaturas sorbiéndoles la sangre. Y Del Río avala todas sus afirmaciones con referencias continuas a las que él considera autoridades en la materia. Es decir, del mar de letras que conforma su propio texto salta a otros libros, los cuales, a su vez, suelen remitir a otros autores y obras. Por ello, la totalidad de argumentos se quedan en el ámbito de lo libresco. Es como si la bruja hubiera encontrado ahí, 
en las páginas de los tratados, un hábitat idóneo en el que nacer, crecer y desarrollarse.

Del mismo modo, en ese mismo capítulo, se otorga una gran relevancia a la marca del diablo, que este imprime en alguna parte del cuerpo, y a la realización de unas ceremonias muy similares a orgías, que se celebran en honor del demonio.

En el capítulo 8, Del Río pretende sustentar sus revelaciones acerca de la brujería, eminentemente femenina, con testimonios en su mayor parte literarios. En concreto, retrocede a la Antigüedad grecolatina y, entre otros, trae a colación a Apuleyo, Virgilio, Ovidio, Tibulo, Propercio, Petronio, Lucano... Y resalta, cómo no, a Circe y Medea. Como bien sabemos, no existían todavía brujas entre los griegos y los romanos, sino solo hechiceras, que, aunque terribles y perniciosas, no habían pactado con el demonio ni acudían a conventículos orgiásticos como los que se describen detalladamente en los tratados de los siglos XVI y XVII. ¿Por qué nos detenemos en las alusiones que utiliza Martín del Río con el fin de sostener sus afirmaciones? Porque este hecho nos permite demostrar un origen y perpetuación librescos del actante que nos ocupa.

En el capítulo 15, el autor sigue cantando las alabanzas de la bruja, y le imputa la realización del acto venéreo con los demonios íncubos, todo esto corroborado por San Jerónimo, San Agustín, San Isidoro e Inocencio VIII. En el capítulo 16, se trata el controvertido asunto de la asistencia a las asambleas nocturnas. En contra de lo que sostienen protestantes como Lutero y Melancton, y católicos como Francisco Samuel, quienes defienden que las brujas acuden solo de pensamiento a tales conventículos, Del Río reconoce el transporte real, aunque en ocasiones el demonio engañe a los sentidos, tal cual hacen expertos como Alberto el Grande, Ciruelo, Grillando, Basino, Remigio... (para este autor la mayoría de los teólogos y juristas de Italia, España y Alemania) ${ }^{11}$. Como respaldo, el autor se vale de actas judiciales (supuestamente representan al

\footnotetext{
11 Un auténtico despliegue de erudición el que ejecuta Martín del Río en este capítulo
} (Disquisiciones: 328-353). 
ámbito de la realidad, con anécdotas e historias narradas por testigos o acusadas); y de las palabras, entre la simple exposición y la anécdota, de, por ejemplo, Micaelis, Pablo Grillando, Pedro Damián, Nicolás Remigio, Balduino Ronseo, Cumano. De estos autores copia varios casos referentes a brujas. En concreto, se detiene bastante en Grillando, que basa sus relatos en su propia actuación como inquisidor, mas él no se presenta como testigo de uno solo de los hechos, sino que se limita a escuchar las confesiones de las acusadas (algunas de estas narraciones las recoge Antonio de Torquemada en su Jardín de flores curiosas). Es como si estuviéramos delante de auténticas joyas de la cuentística popular. ¿Son estos simples invenciones de vecinas de alguna aldea, o, por el contrario, tales mujeres salen del paso exponiendo ante los inquisidores historias que ya conocían de oídas, leyendas que trastocan añadiendo o eliminando detalles $\mathrm{y}$, sobre todo, transformándose ellas mismas en las protagonistas? Con toda probabilidad, nunca lo sabremos ${ }^{12}$.

De manera similar a Grillando actúa el resto de autoridades citadas por Del Río, de modo que resulta difícil distinguir la realidad de la ficción, el acto judicial del cuento popular o la leyenda re-contextualizada. De todos modos, nos movemos todo el tiempo en un ámbito puramente libresco y resulta harto difícil concluir en qué grado se retroalimentan la historia, las elucubraciones que modelan los tratados y las propias letras de ficción.

De hecho, Martín del Río describe el elemento más idiosincrásico de la brujería, que es la reunión, y posiblemente lo construye a base de retazos, cuyas piezas extrae de cada uno de los expertos en los que se basa:

\footnotetext{
${ }^{12} \mathrm{Al}$ hilo de esta reflexión, resulta clave la aclaración que realizan Flores y Masera, 2010, p. 33: "Durante las audiencias, "el narrador-declarante" era conminado a buscar en su memoria [...] algún hecho en particular que fuera significativo para el Inquisidor y a ordenarlo de acuerdo a las preguntas que este hacía, en las que también aportaba información sobre la superstición. Es decir, el inquisidor no sólo escucha, sino que, también con la dirección del discurso en la audiencia, ayuda a la generación de la narración. Este distinguir lo mágico permitido de lo supersticioso, seguir los manuales para evaluar una realidad donde las fronteras entre ambos hechos eran muy difusas; sin embargo, lo que sonseguía era compartir la producción de una expresión narrativa con los declarantes, a pesar de que sus perspectivas fueran, muchas veces, opuestas".
} 
Una vez allí, se enciende por lo general una gran hoguera, siniestra y espantable. El demonio preside sentado en su trono, en forma horrible, casi siempre de macho cabrío o de perro. Se le acercan para adorarle, mas no siempre del mismo modo: unas veces de rodillas, otras andando de espaldas, y ocasionalmente, con las piernas por alto; mas no con la cabeza gacha, sino vuelta, con la barbilla apuntando al cielo. Ofrécenle luego velas de pez o cordones umbilicales, y en señal de homenaje le besan en el culo. [...] Además, de eso, ofrecen a sus hijos al diablo. [...] $\mathrm{O}$ bien le dedican semen eyaculado. [...] $\mathrm{O}$, en fin, ofrecen al demonio la sagrada hostia que retuvieron en la boca al comulgar y allí mismo delante de él la pisotean 13 .

Cometidas estas maldades y execrables abominaciones, y otras parecidas, pasan asentarse a las mesas, a celebrar un convite de manjares que proporciona el diablo, o de los que ha llevado cada cual. A veces bailan antes del banquete, otras después. Suele haber varias mesas, tres o cuatro, repletas de manjares una veces exquisitos, otras muy sosos y desazonados. En ellas toman asiento por orden de dignidad o de hacienda (Disquisiciones: 339 ).

Este teólogo continúa relatando todos y cada uno de los hechos que se suceden en el conventículo, como que las brujas acuden a veces a cara descubierta, a veces enmascaradas; que danzan como enloquecidas con sus demonios tras el banquete y entonan en honor de Satán cantos obscenos; que relatan más tarde sus fechorías y cuanto más graves son, más se alaban y premian; que reciben unos polvos venenosos cuando se despiden, para que con ellos ejecuten sus venganzas; que la vuelta unos la realizan a pie y otros volando, etc. (Disquisiciones: 339-341). Y se da crédito a todos estos despropósitos a causa de la, en teoría, sospechosa similitud entre las confesiones de los brujos y brujas:

Todos los brujos y brujas hacen idénticas confesiones, sin discrepar en el más mínimo detalle; y lo mismo corroboran otras personas libres de su delito y error. Lo reconocen los reos incluso en la hoguera, donde de nada les serviría inventarlo, y cuando se han agotado los tormentos. Lo vano e ilusorio jamás podría contar en su favor con un testimonio tan unánime, concorde y reiterado, ni con el consenso de tantísimas personas, tan diferentes unas de otras en cuento a lugar, tiempo, edad y profesión (Disquisiciones: 351 ).

En cuanto a la metamorfosis de las brujas en diversas especies de animales, este teólogo expone en el capítulo 18 que no son reales, sino que el diablo suele engañarlas de distintas maneras. Resulta francamente interesante cómo el autor

${ }_{13}$ Por poner un ejemplo, la idea del ofrecimiento de los propios hijos la toma Del Río de Binsfeld y la afirmación sobre el semen y la hostia procede de Jaquerio (Disquisiciones: 339). Esto demuestra la tesis del aquelarre de este teólogo como compuesto por diversos retazos procedentes de diferentes autoridades. 
avala esta vez su tesis con un ejemplo extraído de Bartolomé Espíneo, al cual llega la información a través de un "testigo llamado Felipe, de oficio remendón" (Disquisiciones: 365), y nos hallamos ante una de tantas historias sobre transformaciones brujeriles. En otras ocasiones, este teólogo toma sus anécdotas "de oídas", y que gozan de credibilidad en tanto el informante era, en un caso, un hombre religioso y, en otro, un concejal de Malinas. En ese sentido, entramos de lleno en el ámbito de la tradición oral, aunque no podemos determinar en qué medida pertenecen estos relatos al acerbo popular.

El último gran tratado de aquellos que abordaremos en este trabajo es el Discurso acerca de los cuentos de las brujas, de Pedro de Valencia, un texto ineludible si se quiere comprender la conexión existente, en referencia a la brujería, entre realidad y ficción. El título de esta obra resulta muy significativo, puesto que el autor no lo deja al azar y el término "cuento" está escogido muy conscientemente.

Pedro de Valencia tacha de cuentos todas las confesiones brujeriles de las personas imputadas en un archiconocido proceso, aquel que daría pie a estas y otras importante reflexiones acerca de este controvertido movimiento y que generaría decisiones y cambios por parte del Consejo Inquisitorial de la Suprema, hablamos del Auto de Fe de Zugarramurdi de 1610, cuya relación fue realizada por don Juan de Mongastón. Esta compilación de "relatos" cayó en las manos Pedro de Valencia y dio pie a todas las afirmaciones que se recogen en este discurso.

Manuel Antonio Marcos e Hipólito Riesco, en la introducción a la edición que manejamos de este tratado, apuntan a un aspecto que resultará clave a la hora de interpretar los entresijos de la brujería. Los sospechosos de este delito suelen negar taxativamente la acusación, pero las amenazas y la presión a que se ven sometidas empujan a estos reos (sobre todo reas) a confesar unos crímenes que no han perpetrado y lo hacen siguiendo el patrón que van 
marcando aquellos que realizan los interrogatorios ${ }^{14}$. Por otra parte, una vez confiesa uno de los vecinos de la aldea concreta, no tardan en hacerlo otros muchos, repitiendo los mismos moldes de los que ya se sirvió el primero (Discurso: 53).

Los inquisidores (en este caso Becerra y Valle) obran desde su propia obsesión y temor a las brujas. "Para ellos cualquier indicio era una prueba, y cualquier falta de prueba era una manifiesta maquinación del diablo, que desplegaba todo su poder" (Discurso: 57). Y no hay que olvidar a los sacerdotes que asumen la predicación en estos pueblos, pues si comparten esa manía persecutoria por las brujas, contribuirán y mucho a expandir una serie de esquemas fijos sobre estas prácticas, que se sustentarán en sus palabras casi sagradas y una serie de rumores, anécdotas y ejemplos que no se sabe muy bien de dónde proceden exactamente. Frente a estos hombres obsesionados por las sociedades secretas femeninas presididas por el diablo, se alzaban algunos otros que relegaban al mundo de la fábula y de la fantasía todas estas creencias (Discurso: 57).

Entre la materialización más absoluta y los fantasmas de la mente se sitúa la brujería, una supuesta secta de la que todavía no se ha podido desentrañar con exactitud el origen y para la explicación de la cual existen numerosas teorías harto interesantes que no mencionaremos aquí por falta de espacio. ${ }^{15}$ Quizás uno de los mayores problemas con respecto a este "cáncer de la cristiandad" se halla cuando se intenta un acercamiento desde un prisma literario y parte de la respuesta a todos los interrogantes que se plantean en esa intersección de la historia y la antropología y la literatura se encuentra en el camino que va de la rumorología a la cuentística ${ }^{16}$, y que, de alguna manera, esbozan Marcos y

\footnotetext{
${ }^{14}$ La clave estará en el hecho de determinar de dónde exactamente procede la estereotipada idea de la brujería que difunden, por los medios ya aludidos, los inquisidores en cuestión. La aclaración de esta difícil cuestión nos permitiría dilucidar cuánto existe en este fenómeno de popular y cuánto de libresco.

15 Véase Lara Alberola, 2010: 75-82.

${ }_{16}$ Precisamente a este camino remiten Alberto Ortiz y Asunción Rallo (en prensa).
} 
Riesco (Discurso: 98) al abordar la labor del Obispo de Pamplona, Antonio Venegas de Figueroa:

\begin{abstract}
Después de rastrear sobre el terreno los orígenes de lo que él consideraba sencillamente una psicosis brujeril que se había expandido por el valle de Bertizaun, en el que están enclavadas las Cinco Villas, y tras interrogar a múltiples personas que se decían relacionadas con la brujería, el obispo se ratifica en el convencimiento de que aquellas gentes sólo habían comenzado a hablar de brujas a raíz de desencadenarse su cacería en el cercano Pays de Labourd. Muchas personas de la comarca habían acudido al otro lado de la frontera para asistir al macabro espectáculo de la quema de brujas, y allí tuvieron ocasión de conocer los pormenores que concurrieron en la persecución de la secta tan fanáticamente azuzada por Pierre de Lancre. Así fue como se enteraron de las prácticas rituales, de las creencias peculiares y de los poderes demoníacos que se atribuía a aquellas pobres gentes. El impacto psicológico que tales hechos produjeron, los rumores a que dieron lugar y la desatada fantasía ulterior que provocaron, crearon en la población una psicosis generalizada que, en opinión del obispo Venegas, era lo que explicaba la situación que Valle y sus compañeros de Logroño interpretaban de una manera muy distinta (Discurso: 98).
\end{abstract}

De este modo, vemos como se da la confluencia del contenido de las predicaciones, que puede muy bien poseer tanto raigambre popular como libresca (tratadística especializada en supersticiones varias), el patrón planteado en los mismo interrogatorios por parte de los inquisidores, los rumores, anécdotas, creencias..., que se generan por contagio, a partir de otros procesos, autos o persecuciones, en pueblos, ciudades o países vecinos. Y aquello que se consideraba una prueba irrefutable en el seno del proceso de Zugarramurdi, la coincidencia entre las diferentes confesiones, no ha de confundir al lector, pues se trata de una aseveración arriesgada, ya que:

La unívoca orientación de las declaraciones dependía de los más dispares condicionamientos. Cuando los encausados se dieron cuenta de que el único medio de salvar la vida era confesar su pertenencia a la secta [...] se dispusieron a narrar todo cuanto los inquisidores deseaban oír. Sus relatos mezclan las noticias que todo el mundo conocía sobre las prácticas brujeriles, las propias fantasías alucinadas y las insinuaciones que se les hacían en el curso de los interrogatorios. Por si ello fuera poco, [...] no se tuvo muchas veces la cautela de aislar a los encarcelados para que no se transmitieran informaciones ni pudieran ponerse de acuerdo en las declaraciones. No era extraño, pues, que se confesaran, aun siendo inocentes, de cuanto el tribunal tenía empeño en escuchar (Discurso: 108-109).

Por tanto, se entremezclan el origen libresco de la brujería con la vida oral y popular que cobran tales afirmaciones en las zonas rurales, de manera que 
resulta ya imposible desenmarañar ese ovillo de creencias. No obstante, resultan de un gran interés las palabras del propio Alonso de Salazar y Frías, plasmadas en su Segundo memorial: "Saco de las averiguaciones que no hubo brujas ni embrujados en el lugar hasta que se comenzó a tratar y escribir de ellos" (Discurso: 111) ${ }^{17}$.

A todo esto, con la correspondiente sutilidad, Pedro de Valencia lo llamará "los cuentos de las brujas" (tomando el vocablo "cuento" con la suficiente flexibilidad, tal y como lo hacían los escritores y compiladores en los Siglos de Oro). Este autor, en su tratado, toma como un gran relato brujeril la información proporcionada por la relación del proceso, que, sin duda, conoce bien ${ }^{18}$. Y alude continuamente a ejemplos y anécdotas, unos son tomados como cuentos y este intelectual usa verbos como "dicen...", "cuentan..." (Discurso: 269-270). En los casos en que hace referencia a autoridades, sobre todo para avalar su postura escéptica, esas anécdotas se presentan como testimonios: “El Doctor Laguna [...] cuenta que el año de 1545, estando él curando al Duque Francisco de Lorena, fueron presos dos brujos..." (Discurso: 270). Las estructuras lingüísticas son las mismas, pero en unas ocasiones se personaliza en una autoridad y en otras no. Y cuando desea contravenir la credibilidad de algún tratadista, apela a la

17 Por estas mismas palabras, asegurábamos más arriba que el origen de la brujería es libresco, porque realmente no existe hasta que no se comienza a escribir sobre ella. En ese sentido, interesa una cita de Kors y Peters, 1972: 9 (extraída de Stewart y Strathern, 2008: 125): “Los filósofos escolásticos, los teólogos sistemáticos y los demonólogos llegaron a un consenso gradual sobre al carácter y acciones de las brujas".

${ }^{18}$ La relación del Auto de Fe celebrado en la ciudad de Logroño en los días 6 y 7 de noviembre de 1610, realizada y editada por don Juan de Mongastón, comienza con una exposición acerca del desarrollo del propio Auto de $\mathrm{Fe}$, por lo que da cuenta de unos sucesos reales, bien testimoniados, pero inmediatamente inserta lo que él titula Relación de las cosas y maldades que se comenten en la seta de los Bruxos, según relataron en sus sentencias y confesiones. A partir de este momento, el texto se transforma en una explicación acerca de los entresijos de la brujería, en general, pues a partir de los diferentes testimonios, se construye el demoníaco edificio de la secta y se presenta al lector como una verdad incuestionable. Aquí no se debate ni se reflexiona, solo se transmiten una visión de este fenómeno que sirve como vehículo para conocer mejor en qué consiste el crimen que nos ocupa. Y para dar mayor veracidad al discurso se insertan relatos que intentan sustentar este disparate. De este modo, el texto expositivo se enmaraña con el narrativo, hasta que todo él deviene un macrorrelato. En numerosas ocasiones se citan las historias que refieren los diferentes protagonistas de este proceso, como María de Yriart, Iones de Goyburu, Iones de Echalar, María de Echaleco, María de Zozaya, Graciana de Barrenechea, etc., que podrían pasar por consejas de vieja, si no fuera porque se declaran protagonistas de tales cuentos y los ubican en un momento y lugar concreto..., características que podrían cuadrar con otro género típico de la tradición oral: la leyenda. 
condición ficcional de gran parte de los contenidos que circulan acerca de la brujería, como podemos observar cuando expone:

Bien dijera lo mismo Eusebio de dos cuentos que por certísimos y sin réplica alega últimamente el Padre del Río, como quien arroja el áncora sagrada; dice que un burgués había salido al campo con una escopeta, vio en un árbol algunas aves inmundas, cuervos, picazas, etta., tiróles y parecióle haber herido una de ellas; llegando a tomarla, no halló sino solamente una llave que había caído del árbol; llevóla, y en el lugar preguntó a un su amigo si conocía aquella llave, y dijo que sí, y que era de la puerta de fulano; fueron a la casa y abrieron y hallaron a la señora de casa herida en un lado de un arcabuzazo. Eso otro es mejor y lo cuenta como de vista el año 1587 en Calais, estando aquella plaza por de su Majestad, dos capitanías de valones se hallaron de guardia en la puente de Nuelet; dos de estos que estaban por postas vieron pasar sobre sí una nueve negra y les pareció que en ella había murmullos de voces de mucha gente; disparó el uno su arcabuz a la nube y luego cayó delante de sus pies, de la nube, una mujer borracha, desnuda y bien gorda, de mediana edad, atravesado un muslo del balazo; echáronle mano, y ella se fingía fuera de juicio y no decía más "¿Qué gente?, ¿enemigos o amigos?". Añade el Padre del Río una grande exclamación contra los que no creyeren ni se convencieren con estos cuentos. [...] Es de ver y admirarse de un hombre que cuenta esto tan en juicio (Discurso: 304).

Pedro de Valencia no es quien convierte la brujería en un cuento, pero sí quien, con el significativo título de su discurso y con la peculiar visión que adopta, desvela la identidad literaria y ficcional de este complejo fenómeno, aportando a los indagadores de la materia pistas más que valiosas para comprender a la bruja como personaje en las letras aúreas ${ }^{19}$, pues si bien una primera aproximación nos hacía intuir un enorme vacío literario en torno a este arquetipo, hecho que resultaba chocante, la profundización en la tratadística hispánica de los siglos XVI y XVII y sobre todo el acercamiento a Pedro de Valencia, abren nuevas perspectivas y demuestran que la clave está precisamente en ese género literario.

\section{3.- Conclusiones.}

${ }^{19}$ Flores y Masera, 2010, hablan de los "relatos populares de la Inquisición Novohispana", de modo que los testimonios brujeriles que se extraen de los archivos inquisitoriales se toman y analizan como cuentos, lo cual avala nuestra postura al respecto. 
Como hemos visto, para trazar una panorámica de la bruja como personaje de ficción en las letras hay que volver los ojos a la tratadística, sin el estudio de este género no se puede comprender al actante que nos ocupa. No hallamos entre las recopilaciones de cuentos áureos apenas relatos brujeriles, y esto no es concebible a la luz de la condición de arquetipo que detenta la bruja, sobre todo por su presencia en la cuentística que hoy se considera destinada a la infancia, pensemos en las colecciones de Giambattista Basile, Charles Perrault, los hermanos Grimm o Hans Christian Andersen, por poner un ejemplo.

Por otra parte, la España del siglo XIX muestra una mayor consolidación de la bruja en tanto personaje literario y este hecho apunta a un amplio conocimiento de la misma, pues esta pertenece desde hace tiempo al imaginario colectivo; dicha perpetuación en nuestra cultura no puede haberse dado únicamente a partir de las pocas muestras literarias que hemos analizado anteriormente. Forzosamente, ha de pensarse en una considerable transmisión del arquetipo por vía oral-popular.

Esta última afirmación viene avalada por la labor que realiza la tratadística, en tanto compiladora de relatos populares, como bien señala $\mathrm{M}^{\mathrm{a}}$ Jesús Zamora Calvo (2005). En la misma línea irían los archivos de los procesos inquisitoriales, tal y como apuntan Enrique Flores y Mariana Masera en su estudio Relatos populares de la Inquisición novohispana. Ahí tendríamos una segunda fuente de rastreo para determinar cuál ha sido el modo de transmisión del arquetipo brujeril en la cultura hispánica ${ }^{20}$.

Hemos de tener muy en cuenta que la brujería se asienta definitivamente en ese tipo de textos: tratados y archivos-procesos inquisitoriales, que beben, indudablemente, de la tradición oral, pero en los que subyace una determinante base libresca.

\footnotetext{
${ }^{20}$ Flores y Masera, 2010: 29, exponen que "los procesos inquisitoriales constituyen fuentes válidas para conocer las mentalidades y las formas de expresión de los acusados en diferentes períodos $\mathrm{y}$, a pesar de la intermediación, pueden servirnos para estudiar la literatura popular [novohispana], siempre que los tomemos con las debidas reservas". La misma afirmación es válida, claro está, para la literatura popular española.
} 
Estas reflexiones nos llevan a una cuestión muy espinosa sobre el origen mismo del fenómeno en el que nos hemos centrado. ¿La brujería nace de lo popular o de lo libresco? Para responder a esta pregunta habremos de tomar en consideración tanto el sustrato mítico y, por supuesto, hechiceril, como los rumores y habladurías (Stewart y Strathern, 2008) ${ }^{21}$ que se generan en ciertos momentos históricos a causa de determinados condicionantes de carácter social psicológico, antropológico, teológico... y, cómo no, la tarea llevada a cabo por los integrantes de la jerarquía eclesiástica, que terminan de perfilar a la bruja, la dotan de cuerpo material, de entidad propia, y la lanzan, desde el universo puramente mítico, al mundo real, para que recorra Europa y cumpla su cometido $^{22}$.

La bruja, desde ese momento, que se podría ubicar, por ejemplo, en 1486 (publicación del Malleus Maleficarum), existe, pero como ente de ficción, del que nunca se podrá probar la autenticidad. Sí hubo víctimas mortales, y no pocas, en su mayoría mujeres, que sufrieron duras condenas, pero... ¿brujas? No, estas solo protagonizaron historias ficticias ${ }^{23}$, recogidas sobre todo en las relaciones de los procesos y en los tratados, más que en la lírica, el teatro o la narrativa.

\footnotetext{
${ }^{21}$ Stewart y Strathern comentan: "La movilización de la opinión pública es un importante catalizador y, en dicho proceso, el rumor y las habladurías resultan fundamentales" (8); "En el trasfondo de los sucesos comunitarios de las sociedades en las que proliferan tales ideas suele haber comentarios sobre las actividades de brujos y hechiceros. Florecen en la oscuridad, alimentados por los rumores y habladurías, y surgen en el debate público o se convierten en acusaciones en momentos de tensión específica" (p. 16). "El rumor y la habladuría son tan importantes en muchos procesos históricos, porque, al apelar a las predilecciones y sensibilidades de las personas que proporcionan las bases para su verificación. En términos simples, la gente tiende a creer lo que quiere creer, y si se llama bruja a alguien repetidamente, ese alguien se convierte en bruja a ojos de la sociedad" (51).

22 Diana Ceballos (1994: 151-152) (cita extraída de García Soormally, 2011: 90) interpreta la brujería de la siguiente manera: "La bujería es una creencia arraigada en el pueblo, difundida por tradición oral y reforzada, aumentada y amplificada su difusión por las persecuciones inquisitoriales. Es algo que se comunica en las charlas después de las comidas, de camino al laboreo, mientras se está lavando la ropa en el río o mientras se trae agua. Se difunde rápidamente en las capas más bajas de la sociedad, las más ignorantes y, por tanto, las más supersticiosas. Puede llegar a ser una creencia considerada como real. El odio es su motor". Estamos de acuerdo con las palabras de esta autora, pero es necesario resaltar que olvida considerar el origen de esta creencia, pues habla de su difusión y de su amplificación, mas no dilucida si el germen de este fenómeno es popular o libresco. Faltaría llegar a conclusiones fehacientes sobre este hecho.

23 "En los siglos XVI y XVII, el sacerdote no solo busca el pecado, sino también la duda íntima para eliminarla, entendiendo que los seres humanos no necesitan establecer por su cuenta y
} 
Quizás estábamos buscando en el género equivocado o enfocando la cuestión desde un prisma erróneo, porque todo se puede reducir a un único axioma: la brujería en sí es un gran relato 24 , escrito por varias manos y en varios momentos diferentes, y la bruja la protagonista indiscutible de esa magna narración.

No procede seguir interrogándose acerca de la ausencia de la bruja como personaje de relevancia en la literatura de ficción, pues a la luz de nuestra investigación (que ampliaremos en futuros trabajos) la bruja no podría ser más literaria y menos histórica, como se deduce de los propios tratados y procesos: la bruja es el puntal de un cuento fantástico que impregnó, de un modo muy profundo, la realidad.

\section{BIBLIOGRAFÍA}

Beteta Martín, Y. (2011): La querella de las mujeres IX. Súcubos, hechiceras y monstruos femeninos. Estrategias de desautorización femenina en la ficción bajomedieval, Madrid, Almudayna.

Caro Baroja, J. (1995): Las brujas y su mundo, Madrid, Alianza.

Castañega, Fray M. de (2001): Tratado de las supersticiones y hechicerías, ed. José Dueso Alarcón, San Sebastián, De la Luna.

Castro, F. de (s.a), Entremés de las brujas, en Entremeses varios (Libro Nuevo de Entremeses intitulado cómico festejo, su autor Francisco de Castro...), Tomo I, s.l.

riesgo ideas propias sobre el mundo, sino acogerse humildemente a los principios religiosos y dogmas verdaderos; en esta labor de corrección de desvíos la disidencia estaba servida, y fue especialmente trágica en el caso de las brujas, que confesaban sus fantasías oníricas y pactos diabólicos como si se tratara de situaciones vividas realmente, logrando con frecuencia que sus relatos delirantes fueran creídos por los miembros del tribunal que las juzgaba. Estos teólogos o juriconsultos no podían tener nociones acerca de la existencia del psiquismo inconsciente, ni de la disfunción o distorsión que las sustancias psicoactivas provocaban en las mentes de estas aficionadas a evadirse de su triste realidad. Las juzgaban en función de su ortodoxia religiosa, sin haberlas visto nunca a lomos del demonio, ni de machos cabríos o sátiros con alas. La convicción de los inquisidores sobre estos vuelos era consecuencia de la lectura de los diversos tratados antisupersticiosos que circulaban en aquel momento, y que muchos de ellos habían leído con credulidad infantil y máximo respeto a los criterios de autoridad" (Gil, 2011: 237).

${ }^{24}$ Y, como bien dice Gonzalo Gil, “la realidad se configura a través del relato" (2011: 95). 
Cervantes, M. de (1995): El coloquio de los perros, en Novelas Ejemplares II, ed. Harry Sieber, Madrid, Cátedra: 299-359.

Ciruelo, P. (1978): Reprobación de las supersticiones y hechicerías, ed. Alva V. Ebersole, Valencia, Albatros Hispanófila Ediciones.

Fernández, L. (1976): Égloga o Farsa del Nascimiento, en Farsas y Églogas, ed. Ma Josefa Canellada, Madrid, Castalia.

Fields, D. (2012): El protagonismo de la bruja tutelar en el cuento folklórico maravilloso: análisis de personajes, argumentos, funciones y motivos en un corpus hispánico y universal, Departamento de Filología Española, Universidad de Valencia.

Flores, E. y Masera, M. (2010): Relatos populares de la Inquisición novohispana, Madrid, CSIC-UNAM.

García Soormally, M. (2011): Magia, hechicería y brujería. Entre "La Celestina" y Cervantes, Sevilla, Renacimiento.

Gil González, G. (2011): A la luz de los prodigios. Almas, demonios y seres evanescentes, mitos y mundos en el Siglo de Oro, Madrid, Miraguano.

Lara Alberola, E. (2008): “El papel de la hechicería en la picaresca española”, Bulletin of Hispanic Studies, 85: 471-485.

Lara Alberola, E. (2010): Hechiceras y brujas en la literatura española de los Siglos de Oro, Valencia, Universidad de Valencia.

Lobato, M. L. (ed.) (2003): Loas, entremeses y bailes de Agustín Moreto, vol. 1, Kassel, Reichenberger.

Moreto, A. (1930): Entremés famoso de las brujas, en El desdén con el desdén: entremeses, Madrid, Compañía Ibero-Americana de Publicaciones.

Medrano, J. (1998): Silva curiosa, ed. Mercedes Alcalá Galán, Nueva York, Peter Lang. Navarrete, B. de (2001): La pícara Justina, ed. Pablo Jauralde Pou, Madrid, Espasa-Calpe.

Ortiz, Alberto (en prensa): "Letras del encanto. Introducción a la magia culta en la literatura hispánica del siglo XVI", en E. Lara y A. Montaner (eds.), La magia en la literatura española del Renacimiento, Salamanca, Semyr.

Pérez, J. (2010): Historia de la brujería en España, Madrid, Espasa.

Quevedo, Francisco de (2001): El Buscón, en La novela picaresca, ed. Pablo Jauralde Pou, Madrid, Espasa Calpe.

Quiñones de Benavente, L. (atribuido) (1712): Entremés de las brujas fingidas y berza en boca, Ms. 14089 de la BNE. 
Rallo, A. (en prensa): “De la noticia al relato novelesco. La magia en la miscelánea y el diálogo renacentistas", en E. Lara y A. Montaner (eds.), La magia en la literatura española del Renacimiento, Salamanca, Semyr.

Río, M. del (1991): La magia demoníaca. Parte II de las Disquisiciones mágicas, ed. Jesús Moya, Madrid, Hiperión.

Rojas, F. de (1993): La Celestina, ed. Dorothy Severin, Madrid, Cátedra.

Sandoval, Fray P. de (1955-56): Historia de los hechos del Emperador Carlos V, ed. Carlos Seco Serrano, Madrid, Atlas.

Stewart, P. y Strathern, A. (2008): Brujería, hechicería, rumores y habladurías, Madrid, Akal.

Torquemada, A. de (2000): Jardín de flores curiosas, San Sebastián, Roger Editor.

Valencia, P. de (1997): Obras Completas VII. Discurso acerca de los cuentos de las brujas, León, Secretariado de publicaciones de la Universidad de León.

Vicente, G. (1984): Auto das fadas, en Compilaçam de todas las obras de Gil Vicente, Biblioteca de Autores Portugueses, Lisboa, Imprensa Nacional: Casa da Moeda.

Zamora Calvo, M. J. (2005): Ensueños de razón. El cuento inserto en tratados de magia, Madrid-Frankfurt, Iberoamericana-Vervuert. 